\title{
Manejo do solo com plantas adubadeiras e rochagem e os efeitos no crescimento do milho
}

A utilização de adubação verde visa a proteção do solo, melhoria de suas características além de fornecer nutrientes para as plantas, da mesma forma, a rochagem vem a ser uma fonte alternativa para remineralização dos solos sendo importante o aproveitamento dessas fontes para adubação, principalmente os resíduos de mineração, buscando um destino ambientalmente correto para o rejeito. Neste sentido, este trabalho tem como objetivo avaliar o desempenho agronômico do milho em diferentes manejos com adubos verdes, pó de rocha e o efeito entre os mesmos sobre o incremento da produtividade na cultura do milho. 0 delineamento experimental foi em blocos ao acaso em esquema fatorial $6 \times 5$ equivalente a 6 tratamentos e 5 repetições. Os tratamentos foram T1 (somente 0 solo, sem rochagem e adubação verde), T2 (Mucuna-preta), T3 (Feijão-guandu), T4 (Rochagem), T5 (Mucuna-preta + rochagem) e T6 (Feijão-guandu + rochagem), a quantidade de pó de rocha utilizado foi em uma proporção de 2 T.ha- ${ }^{-1}$. Os parâmetros analisados foram: matéria seca das plantas adubadeiras (MSPA), matéria seca do milho (MSM), altura de plantas de milho $\left(\mathrm{HP}^{1}\right.$ e $\left.\mathrm{HP}^{2}\right)$ e Diâmetro do coleto do milho ( $\left.\mathrm{DC}^{1} \mathrm{e} \mathrm{DC}^{2}\right)$ aos 30 dias após a semeadura (DAS) e ao final do experimento, tamanho de espigas (TE), diâmetro de espigas (DE), peso de mil grãos (PM) e rendimento de grãos (RG). O tratamento T3 promoveu os maiores resultados para as variáveis MSPA, MSM, HP1 aos 30 DAS, PM e RG, sendo superior a todos os outros tratamentos nas respectivas variáveis, nas demais os tratamentos não diferiram entre si. De forma geral dos tratamentos T3 e T5 promoveram os melhores resultados na cultura do milho.

Palavras-chave: Adubação verde; Rochagem; Sucessão de culturas; Agroecologia; Adubação alternativa.

\section{Soil management with fertilizer plants and stonemeal and the effects on corn growth}

\begin{abstract}
The green manure use aims the soil protection, its characteristics improvement in addition to provide nutrients for the plants, likewise, the stonemeal becomes an alternative source for soil remineralization being important these sources utilization for fertilization, mainly the mining residues seeking a correct environmentally destination for the tailing. In this sense, this work aims to evaluate the corn agronomic performance in different managements with green manures, rock powder and the effect between them on the productivity increment in the corn culture. The experimental design was in randomized blocks in a factorial scheme $6 \times 5$ equivalent to 6 treatments and 5 repetitions. The treatments were T1 (only the soil, without stonemeal and green manure), T2 (Black mucuna), T3 (Guandu bean), T4 (Stonemeal), T5 (Black mucuna + stonemeal) and T6 (Guandu bean + stonemeal), the used rock powder amount was in a proportion of 2 T.ha- ${ }^{-1}$. The analyzed parameters were: fertilizer plants dry matter (FPDM), corn dry matter (CDM), corn plants height ( $\mathrm{HP}^{1}$ and $\mathrm{HP}^{2}$ ) and Corn collar diameter (DC ${ }^{1}$ and $\mathrm{DC}^{2}$ ) at 30 days after sowing (DAS) and at the experiment end, cobs size (CS), cobs diameter (CD), a thousand grains weight (TG) and grains yield (GY). The treatment T3 promoted the highest results for the variables FPDM, CDM, HP ${ }^{1}$ at $30 \mathrm{DAS}, \mathrm{TG}$ and $\mathrm{GY}$, being superior to all the other treatments in the respective variables, in the others the treatments didn't differ between them. In general, the treatments T3 and T5 promoted the best results in the corn crop.
\end{abstract}

Keywords: Green manure; Stonemeal; Crops succession; Agroecology; Alternative fertilization

Topic: Ciências do Solo

Reviewed anonymously in the process of blind peer
Received: 02/07/2021

Approved: $27 / 07 / 2021$
Vitor Lunelli Araujo

Universidade Federal do Pará, Brasi http://lattes.cnpq.br/3998571596843557 http://orcid.org/0000-0003-4529-4789

vitorlunellilpi@gmail.com

Sandra Andréa Santos da Silva (iD Universidade Federal do Pará, Brasil http://lattes.cnpq.br/5742329435239170 http://orcid.org/0000-0002-1742-1544 sandrasilva@ufpa.br

Vivian Dielly da Silva Farias (D) Universidade Federal do Pará, Brasil http://lattes.cnpq.br/0775979770122595 http://orcid.org/0000-0003-0395-7839 vivianfarias@ufpa.br

\begin{tabular}{l} 
Maysa Lorrane Medeiros de Araújo \\
Universidade Federal do Pará, Brasil \\
http://lattes.cnpq.br/4206967958961138 \\
\hline http://orcid.org/0000-0002-9307-3166 \\
maysamedeiros97@gmail.com \\
Jhonn Lenon de Morais Bizerra DD \\
Universidade Federal do Pará, Brasil \\
http://lattes.cnpq.br/9505273295557372 \\
http://orcid.org/0000-0001-7656-8733 \\
jhonnmorais2018@gmail.com \\
Matheus Hofmann Trevisan (D) \\
Universidade Federal do Pará, Brasil \\
http://lattes.cnpq.br/6490559067500790 \\
http://orcid.org/0000-0001-7398-5654 \\
mateustrevis@hotmail.com
\end{tabular}

voneia de Freitas dos Santos Universidade Federal do Pará, Brasil http://lattes.cnpq.br/4417187267989409 http://orcid.org/0000-0001-8252-5166 ivoneia.agro@outlook.com

Gustavo Gomes Lima (iD

Universidade Federal do Pará, Brasil http://lattes.cnpq.br/5093684249735661 http://orcid.org/0000-0002-5897-8154 gustavosp7940@gmail.com

Rafael Oliveira da Silva (i)

Universidade Federal do Pará, Brasil http://lattes.cnpq.br/5967744930098218 http://orcid.org/0000-0002-4728-2493 rafaelosilva21@gmail.com
0

DOI: $10.6008 / C B P C 2179-6858.2021 .007 .0003$
Referencing this:

ARAUJO, V. L.; SILVA, S. A. S.; FARIAS, V. D. S.; ARAÚJO, M. L. M.; BIZERRA, J. L. M.; TREVISAN, M. H.; SANTOS, I. F.; LIMA, G. G.; SILVA, R. $O$.. Manejo do solo com plantas adubadeiras e rochagem e os efeitos no crescimento do milho. Revista Ibero Americana de Ciências Ambientais, v.12, n.7, p.25-37, 2021. DOI:

http://doi.org/10.6008/CBPC2179-6858.2021.007.0003 


\section{INTRODUÇÃO}

O solo representa um bem social limitado de riqueza imensurável para a sociedade, tendo em vista que sua utilização ao longo das gerações para a produção agrícola agrega valor ao mesmo e reafirma sua importância para a humanidade, entretanto sua utilização de forma inconsciente pode implicar no comprometimento das gerações futuras (PINHEIRO, 2015; MIRANDA, 2018).

A consequência do manejo do solo de forma inadequada resulta no abandono de áreas antes produtivas por conta dos baixos índices de produtividades das culturas e ocorrência de processos erosivos. O uso do fogo torna-se outro fator que provoca degradação dos solos, esse manejo a longo prazo causa prejuízos para a fauna do solo, para as características físicas, químicas, e resulta em pouca ou nenhuma matéria orgânica no solo (LONGO et al., 2011). No Brasil, 16\% do território (1,34 milhão de km²) estão suscetíveis à desertificação. Essa área atinge 1.490 municípios de acordo com dados do Ministério do Meio Ambiente (FAO, 2018).

Ao longo dos anos, e com o advento da revolução verde a agricultura ficou mais tecnificada e intensiva, aumentando-se consideravelmente a produção agrícola, entretanto, essas práticas preconizadas por esse período evolutivo da agricultura resultaram em aumento de perda de solo e degradação, dependência de insumos externos para assegurar as produtividades e perda da biodiversidade (HENRIQUES, 2009; MATZEMBACHER et al., 2020)

As formas de manejo que preconizam a conservação do solo sempre foram utilizadas na agricultura, sendo alterativas viáveis e sustentáveis para sua manutenção e conservação, dentre estes destaca-se a adubação verde, como forma de contribuir com o aumento da matéria orgânica no solo, que está associada diretamente com a melhoria das qualidades físicas e biológicas com o aumento de microrganismos no solo, além de apresentar quantidades consideráveis de macro e micro nutrientes em sua biomassa, dentre estes destaca-se o Nitrogênio (CAVALCANTE et al., 2012; BATISTA et al., 2013). Outro manejo empregado na recuperação da fertilidade do solo é pela técnica do uso da rochagem. Esta permite acrescentar quantidades de rochas trituradas sobre o solo, estas rochas apresentam naturalmente uma quantidade de minerais, principalmente, $\mathrm{P}, \mathrm{K}, \mathrm{Ca}$ e $\mathrm{Mg}$, que consequentemente aumentam a fertilidade do solo através da liberação desses nutrientes, além de melhorar sua estrutura.

Na região da transamazônica e Xingu as práticas de manejo do solo utilizando a adubação verde remota de meados de 1990, difundida pelo projeto roça sem queimar que tinha como objetivo preconizar alternativas ao uso do fogo para implantação de cultivos agrícolas, principalmente lavouras cacaueiras. Já a prática da rochagem é incipiente na região, havendo a necessidade de se realizarem estudos que possam comprovar sua viabilidade aqui na região. Mais ainda, deve-se buscar alternativas para potencializar a utilização da rochagem e da adubação verde e da associação de ambos para promover benefícios ao solo e as plantas, além de se consolidar um modelo de agricultura que seja viável para a região.

Este trabalho tem por objetivo avaliar o desempenho agronômico do milho em diferentes manejos com adubos verdes, pó de rocha e o efeito entre os mesmos sobre o incremento da produtividade na cultura 
do milho.

\section{MATERIAIS E MÉTODOS}

\section{Histórico e caracterização da área}

O experimento foi realizado em campo no município de Brasil Novo - PA, no Sítio Paraíso Orgânico localizado a 317'37,4" S de latitude e 52³4'33,2' W de longitude, na vicinal 16 a 4 km de distância da sede do município e teve como duração o período de setembro de 2019 a junho de 2020. O clima da região é classificado como Equatorial Quente e Úmido apresentando três meses secos (IBGE, 2002), a classificação climática da região segundo a definição de Köppen é de clima megatérmico das regiões tropicais e subtropicais, clima de monção - Am e clima megatérmico das regiões tropicais e subtropicais, clima tropical com estação seca no inverno - Aw (BRASIL, 2011).

A área de condução do experimento tem como histórico de uso o plantio de cacaueiro entre os anos de 1980 e 1990, abandono da área e pousio entre os anos de 1990 e 2005, replantio de cacaueiros no ano de 2006 e posterior pousio até o ano de 2011,quando ocorreu novamente o plantio de cacau no ano de 2012, sendo abandonado o cultivo no ano posterior, permanecendo sem utilização para fins agrícolas até o ano de 2015 quando ocorreu a supressão da vegetação para o plantio de culturas anuais, em 2018 a área foi utilizada para o plantio de hortaliças, e no ano de 2019 ocorreu a implantação do experimento.

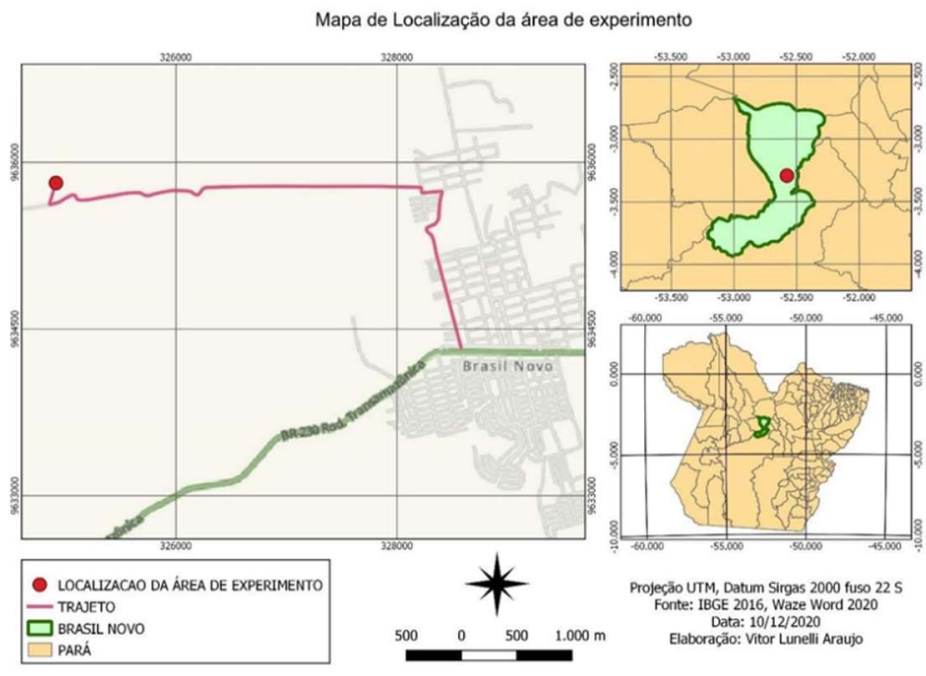

Figura 1: Mapa de localização da área do experimento.

O solo do local do experimento consiste em um Latossolo Vermelho Distrófico, sendo a coleta para análises químicas ocorrida no mês de setembro de 2019 seguindo a metodologia proposta por E Teixeira et al. (2017), as análises químicas foram realizadas em laboratório de solos e os resultados foram interpretados no mês de novembro e tiveram os seguintes resultados: $\mathrm{pH} \mathrm{H}_{2} \mathrm{O}=5,1$ (médio); $\mathrm{P}$ Mehlich $=5 \mathrm{mg} / \mathrm{dm}^{3}$ (baixo); $\mathrm{K}=76 \mathrm{mg} / \mathrm{dm}^{3}$ (alto); $\mathrm{Ca}=1,3 \mathrm{Cmol} \mathrm{c} / \mathrm{dm}^{3}$ (baixo); $\mathrm{Mg}=0,6 \mathrm{Cmol} \mathrm{c} / \mathrm{dm}^{3}$ (médio); $\mathrm{Al}=0,4 \mathrm{Cmol} \mathrm{c} / \mathrm{dm}^{3}$ (médio); $\mathrm{H}+\mathrm{Al}=5,8 \mathrm{Cmol} \mathrm{c} / \mathrm{dm}^{3}$; Matéria Orgânica = 2,5 dag/kg (média); CTC $(\mathrm{T})=7,9 \mathrm{Cmol} \mathrm{c} / \mathrm{dm}^{3}$ (médio); $\%$ = 16 (baixo); V\%= 26,7 (baixo), seguindo a metodologia proposta por Brasil et al. (2020).

O pó de rocha utilizado vem da Rocha Gnaisse extraída de uma jazida localizada em Medicilândia/PA, 
nas coordenadas 326'22" S, 52ำ5'55.6” W sob mineração pela Rocha Engenharia. O material passou por análise química o foram encontradas grandes concentrações de alguns nutrientes, principalmente para P e K (Tabela 1).

Tabela 1: Valores de nutrientes obtidos da análise química do pó de rocha.

\begin{tabular}{lllllllll}
\hline $\mathbf{p H ~} \mathbf{H}_{2} \mathbf{O}$ & $\mathbf{N}-$ Total & $\mathbf{P}$ & $\mathbf{K}$ & $\mathbf{C a}$ & $\mathbf{M g}$ & $\mathbf{S}$ & $\mathbf{C T C}$ & $\mathbf{V} \%$ \\
\hline & $\%$ & $\mathbf{M g} / \mathbf{d m}^{\mathbf{3}}$ & $\mathbf{C m o l c} / \mathbf{d m}^{\mathbf{3}}$ & $\mathbf{\%}$ & & & & \\
\hline 8,6 & 0,14 & 91 & 750 & 12,2 & 1,4 & 14 & 17,1 & 95,3 \\
Alcalinidade & Alto & Alto & Elevado & Alto & Alto & Alto & Alto & M. Alto \\
\hline
\end{tabular}

Fonte: Teixeira et al. (2017).

Foram realizadas análises de elementos tóxicos, necessário para identificar as quantidades desses elementos para enquadramento na resolução № 420 de 2009 do CONAMA, que orienta sobre as quantidades máximas permitidas para uso em fins agrícolas (tabela 2).

Tabela 2: Elementos tóxicos presentes no pó de rocha, valores baseados no indicador de "prevenção".

\begin{tabular}{llll}
\hline Cromo & Cádmio & Chumbo & Níquel \\
\hline $\mathrm{mg} / \mathrm{dm}^{3}$ & & & \\
\hline 0,44 & 0,14 & 1,58 & 0,90 \\
\hline Baixo & Baixo & Baixo & Baixo \\
\hline
\end{tabular}

Fonte: CONAMA (2009).

\section{Delineamento experimental}

O delineamento experimental foi realizado em blocos ao acaso com 6 tratamentos e 5 repetições, os tratamentos utilizados foram: T1 - solo: somente o milho (Mi); T2 - Mucuna - Preta (M); T3 - Feijão Guandu (FG); T4 - Rochagem (Ro); T5 - Mucuna- Preta + rochagem (M + Ro); T6 - Feijão - Guandu + Rochagem (FG + Ro). A área dos tratamentos é de $2 \mathrm{~m}$ de largura por $2 \mathrm{~m}$ de comprimento totalizando $4 \mathrm{~m}^{2}$ cada.

\section{Condução do experimento}

O preparo do solo ocorreu no mês de setembro de 2019 utilizando grade de arrasto intermediária. 0 pó de rocha passou por peneiramento e foi utilizada uma granulometria em uma faixa $<2.00 \mathrm{~mm}$ e $>1.00 \mathrm{~mm}$, aplicado após a gradagem na quantidade de 2 t.ha $^{-1}$ conforme Martins et al. (2011), em cada parcela de tratamento, precedendo o semeio de adubos verdes.

Para os tratamentos com adubação verde, sendo para as espécies com a Mucuna-Preta (Stilozobium aterrimum Piper \& Tracy) e o Feijão-guandu (Cajanus cajan L.) foram utilizadas 15 sementes por $\mathrm{m}^{-1}$ sendo 3 sementes em cada berço espaçadas em $20 \mathrm{~cm}$ entre plantas e $50 \mathrm{~cm}$ entre linhas, ambas foram semeadas manualmente. A irrigação foi realizada por aspersão com mini canhão distanciadas em cinco metros entre aspersores e cinco metros entre as linhas de distribuição.

O corte foi realizado no início da floração quando foram coletadas as respectivas massas verdes das plantas adubadeiras utilizando moldura em madeira com as dimensões de 0,5 $\mathrm{m} \times 0,5 \mathrm{~m}$ com área de 0,25 $\mathrm{m}^{2}$. Após o corte, o material foi levado a estufa de circulação forçada com temperatura de $70 \circ \mathrm{C}$ até atingir peso constante para se obter a massa seca das plantas adubadeiras (MSPA), posteriormente o material foi redistribuído novamente sobre o solo nos respectivos tratamentos. O semeio do milho ocorreu aos 52 dias 
após o corte (DAC).

As sementes de milho utilizados foram da variedade BRS Sol da Manhã adaptada aos solos com baixa fertilidade e com alto potencial produtivo, atingindo em torno de $7500 \mathrm{~kg} \cdot \mathrm{ha}^{-1}$ em solos com boa disponibilidade de nitrogênio e $4000 \mathrm{~kg}$.ha-1em solos com baixa disponibilidade de nitrogênio (EMBRAPA, 1990) e foi adquirido na Secretaria de Agricultura do Município. O semeio foi realizado com semeadora manual (matraca), o espaçamento foi de 0,50 m entre linhas com 3 sementes por metro linear com stand de 60.000 plantas/ha (OLIVEIRA et al., 2018).

Durante a condução foram realizadas duas capinas manuais, duas aplicações de extrato de Neem com Citronela na proporção de 1 litro de extrato para 5 litros de água para controle da lagarta-do-cartucho (Spodoptera frugiperda) adaptado de Nunes et al. (2013), e uma aplicação de Calda de Cinzas na proporção de $1,25 \%$ para fortificação das plantas e controle de pragas e doenças, adaptado de Leite et al. (2016).

\section{Coleta e processamento de dados}

Aos 30 dias após a semeadura (DAS) ocorreu a medição da altura das plantas (HP) e diâmetro do coleto (DC) sendo repetido ao final do experimento; as medições de tamanhos de espigas (TE), diâmetro de espigas (DE), peso de mil grãos (PM) e rendimento de grãos em kg.ha-1 $(R G)$ e matéria seca do milho (MSM) foram realizadas após a colheita.

Os dados de matéria seca das plantas adubadeiras (MSPA), matéria seca do milho(MSM), altura das plantas de milho aos $30 \mathrm{DAS}\left(\mathrm{HP}^{1}\right)$, diâmetro do coleto aos $30 \mathrm{DAS}\left(\mathrm{DC}^{1}\right)$, altura das plantas de milho ao final do experimento $\left(H P^{2}\right)$, diâmetro do coleto ao final do experimento $\left(D C^{2}\right)$, comprimento de espigas (CE), diâmetro de espigas (DE), peso de mil grãos (PM) e rendimento dos grãos em kg.ha-1 $(R G)$ foram submetidos a análise estatística de comparação múltipla de médias pelo teste Scott-Knott a 5\% de probabilidade no Software Sisvar 5.6.

\section{RESULTADOS}

As variáveis produção de matéria seca das plantas adubadeiras (MSPA) obteve resultado significativo, sendo que o tratamento T3 com Feijão-guandu obteve os melhores resultados, 24,75 T.ha-1 (tabela 3), possibilitando o incremento de grandes quantidades de biomassa seca, proporcionando aporte de matéria orgânica ao sistema de produção. Os tratamentos T2 e T6 produziram 11,38 e 12,64 T.ha-1 de matéria seca respectivamente, seguido do tratamento $T 5$ com produção de 12,52 t.ha $^{-1}$ não diferindo estatisticamente entre si, mas contribuindo de forma positiva no incremento de matéria orgânica. Os tratamentos T1 e T4 não receberam adubação verde, pois tiverem sua vegetação capinada durante a condução do experimento.

A contribuição para o aporte de matéria orgânica do tratamento T3 contribuiu para as maiores quantidades de matéria seca para o milho, afirmando que quando maior a produção de biomassa da planta adubadeira maior é o incremento para a cultura sucessiva, isso foi observado no tratamento T3 na variável MSM que foi superior a todos os outros tratamentos e diferiu dos demais estatisticamente, resultando na produção de 4758,25 T.ha ${ }^{-1}$ de MSM. Os demais tratamentos foram inferiores e não apresentaram diferenças 
significativas, sendo o tratamento T1 o que obteve a menor produção, 2866,32 T.ha-1 ${ }^{-1}$, seguido do tratamento T6 com 2974,57 T.ha ${ }^{-1}$. Acordo com os dados obtidos nesta pesquisa o incremento teve ordem decrescente observando os seguintes tratamentos, $\mathrm{T} 3>\mathrm{T} 5>\mathrm{T} 4>\mathrm{T} 2>\mathrm{T} 6>\mathrm{T} 1$ em teores de matéria orgânica acumuladas sobre o solo.

Tabela 3: Produção de matéria seca das plantas adubadeiras (MSPA), matéria seca do milho (MSM), altura de plantas aos 30 DAS (HP'), diâmetro do coleto aos 30 DAS $\left(\mathrm{DC}^{1}\right)$, altura de plantas ao final do experimento $\left(\mathrm{HP}^{2}\right)$, diâmetro do coleto ao final do experimento $\left(D C^{2}\right)$, comprimento de espigas (CE), diâmetro das espigas (DE), peso de mil grãos (PM), rendimento de grãos (RG) com e sem a Rochagem.

\begin{tabular}{|c|c|c|c|c|c|c|c|c|c|c|}
\hline TRATAMENTO & $\begin{array}{l}\text { MSPA } \\
\left(T^{\prime} \cdot \text { ha }^{-1}\right)\end{array}$ & $\begin{array}{l}\text { MSM (kg.ha- } \\
\text { 1) }\end{array}$ & $\begin{array}{l}H^{1} \\
(\mathrm{~cm})\end{array}$ & $\begin{array}{l}C^{1} \\
(\mathrm{~cm})\end{array}$ & $\begin{array}{l}\mathrm{HP}^{2} \\
(\mathrm{~cm})\end{array}$ & $\begin{array}{l}C^{2} \\
(\mathrm{~cm})\end{array}$ & $\begin{array}{l}\text { CE } \\
(\mathrm{cm})\end{array}$ & $\begin{array}{l}\mathrm{DE} \\
(\mathrm{mm})\end{array}$ & $\begin{array}{l}\text { PM } \\
\text { (g) }\end{array}$ & $\begin{array}{l}\text { RG } \\
\text { (kg.ha-1) }\end{array}$ \\
\hline T1 & ----- & $2866,32 b$ & $33,61 b$ & $0,045 b$ & $164 \mathrm{a}$ & 9,51 a & $7,90 \mathrm{a}$ & $\begin{array}{l}30,89 \\
a\end{array}$ & $\begin{array}{l}262,2 \\
d\end{array}$ & $\begin{array}{l}1816,8 \\
\text { d }\end{array}$ \\
\hline $\mathrm{T} 2$ & $11,38 \mathrm{~b}$ & $3000,72 b$ & $38,75 \mathrm{~b}$ & $0,057 \mathrm{a}$ & $180 \mathrm{a}$ & $\begin{array}{l}10,35 \\
a\end{array}$ & 9,77 a & $\begin{array}{l}36,80 \\
a\end{array}$ & $\begin{array}{l}278,4 \\
c\end{array}$ & $\begin{array}{l}3716,4 \\
c\end{array}$ \\
\hline T3 & $24,75 \mathrm{a}$ & $4758,25 \mathrm{a}$ & 43,39 a & $0,065 \mathrm{a}$ & $193 \mathrm{a}$ & $\begin{array}{l}12,75 \\
a\end{array}$ & $\begin{array}{l}12,99 \\
a\end{array}$ & $\begin{array}{l}40,84 \\
a\end{array}$ & $\begin{array}{l}309,6 \\
a\end{array}$ & $\begin{array}{l}6331,8 \\
a\end{array}$ \\
\hline T4 & ----- & $3097,11 \mathrm{~b}$ & $34,45 \mathrm{~b}$ & $0,045 \mathrm{~b}$ & $192 \mathrm{a}$ & $\begin{array}{l}10,71 \\
a\end{array}$ & 9,49 a & $\begin{array}{l}36,39 \\
a\end{array}$ & $\begin{array}{l}277,6 \\
c\end{array}$ & $\begin{array}{l}2362,8 \\
d\end{array}$ \\
\hline T5 & $14,52 \mathrm{~b}$ & $3719,09 \mathrm{~b}$ & $37,73 \mathrm{~b}$ & 0,059 a & $184 \mathrm{a}$ & $\begin{array}{l}11,20 \\
a\end{array}$ & $\begin{array}{l}11,50 \\
a\end{array}$ & $\begin{array}{l}39,39 \\
a\end{array}$ & $\begin{array}{l}298,2 \\
b\end{array}$ & $\begin{array}{l}4995,0 \\
b\end{array}$ \\
\hline T6 & $12,64 \mathrm{~b}$ & 2974,57 b & $35,45 \mathrm{~b}$ & $0,049 \mathrm{~b}$ & $176 a$ & $\begin{array}{l}10,30 \\
a\end{array}$ & $9,34 \mathrm{a}$ & $\begin{array}{l}33,60 \\
a\end{array}$ & $\begin{array}{l}274,6 \\
c\end{array}$ & $\begin{array}{l}3174,6 \\
c\end{array}$ \\
\hline CV\% & 43,36 & 26,70 & 9,30 & 16,17 & 15,49 & 16,38 & 25,17 & 22,47 & 2,06 & 25,24 \\
\hline
\end{tabular}

T1: Solo (sem adubação verde e sem rochagem); T2: Mucuna-preta; T3: Feijão-guandu; T4: Rochagem; T5: Mucunapreta + rochagem; T6: feijão-guandu + rochagem. Médias seguidas das mesmas letras não diferem significativamente pelo teste de Scott-Knott a $5 \%$ de probabilidade.

Os resultados para $\mathrm{HP}^{1}$ e aos 30 DAS apresentaram diferenças significativas, o T3 obteve os melhores resultados, diferindo dos demais tratamentos com valores de 43,39 $\mathrm{cm}$ para $\mathrm{HP}^{1}$, o menor valor foi encontrado no tratamento $\mathrm{T} 1 \mathrm{com} 33,61 \mathrm{~cm}$, entretanto não diferiu dos tratamentos T2, T4, T5 e T6, com valores de $37,75 \mathrm{~cm}, 34,45 \mathrm{~cm}, 37,73 \mathrm{~cm}$ e $35,45 \mathrm{~cm}$ respectivamente.

A variável $D^{1}$ apresentou diferenças significativas sendo o tratamento T3 o que apresentou os maiores valores, 0,065 cm para DC', T1 e T4 apresentaram os mesmos resultados, 0,045 cm, não diferindo dos tratamentos T2, T5 e T6 com 0,057 cm, 0,059 cm e 0,049 cm, respectivamente. Mesmo havendo diferenças entre o tratamento $\mathrm{T} 3$ dos demais para as variáveis $\mathrm{HP}^{1}$ e $\mathrm{DC}^{1} \mathrm{o}$ mesmo não foi observado para as variáveis $\mathrm{HP}^{2}$ e $\mathrm{DC}^{2}$ ao final do experimento, onde não houve diferenças significativas entre os tratamentos (tabela 3).

Outras variáveis que não apresentaram diferença estatística foram o comprimento de espigas (CE) e diâmetro de espigas (DE), sendo estas variáveis relacionadas a espiga e consequentemente aos parâmetros de qualidade das mesmas, o tratamento T3 apresentou as maiores médias para estas variáveis, 12,99 cm e 44,84 mm, a menor média foi observada no tratamento $T 1 \mathrm{com} \mathrm{7,90} \mathrm{cm}$ para comprimento de espigas e 30,89 mm para diâmetro de espigas. Mesmo não havendo diferença para essas variáveis citadas anteriormente as variáveis peso de mil grãos e rendimento de grãos tiveram diferenças significativas em seus resultados, sendo o tratamento T3 foi o que apresentou os melhores resultados com peso de mil grãos de 309,6 g e rendimento de grãos de $6331,8 \mathrm{~kg} \cdot \mathrm{ha}^{-1}$, seguido do tratamento T5 com peso de mil grãos de 298,2 g e rendimento de grãos de $4995 \mathrm{~kg} \mathrm{ha}^{-1}$. Os tratamentos T6 e T2 não diferiram estatisticamente, 
apresentando 274,6 g e 3174,6 kg.ha-1 para peso de mil grãos e rendimento de grãos em T6, 278,4 g e 3716,4 kg.ha-1 para peso de mil grãos e rendimento de grãos em T2. Mesma forma o tratamento somente com rochagem (T4) e somente o solo, sem rochagem e adubação verde (T1) não diferiram estatisticamente, sendo encontrados para T4 277,6 g para peso de mil grãos e 2362,8 kg.ha-1 para rendimento de grãos e T1 com 262,2 g para peso de mil grãos e 1816,8 kg.ha-1 para rendimento de grãos.

Para as variáveis MSPA, MSM, HP1, PM e RG analisadas neste experimento, o tratamento T3 com feijão guandu foi o que obteve os melhores valores, diferindo estatisticamente dos demais, garantindo a superioridade deste em relação aos outros e contribuindo positivamente no incremento da produção e produtividade final da cultura do milho.

$\mathrm{O}$ tratamento $\mathrm{T} 1$, solo natural sem rochagem e adubação verde e o tratamento $\mathrm{T} 4$ onde houve a incorporação de 2 t.ha ${ }^{-1}$ de pó de rocha não diferiram estatisticamente entre si para a maioria das variáveis analisadas, somente na variável PM T4 foi superior, apresentando valores de 277,6 g contra 262,2 g para o tratamento T1.

Os tratamentos em que houve a junção entre adubação verde e rochagem, Mucuna-preta com rochagem (T5) e Feijão-guandu com rochagem (T6), não foram superiores ao tratamento T3 (tabela 3), que apresentou os melhores resultados. Entretanto, pôde-se observar que o tratamento de Mucuna-preta com rochagem (T5), foi superior ao tratamento somente com Mucuna-preta (T2) nas variáveis PM e RG, nas demais, não apresentou diferenças significativas. Sobre os resultados do tratamento de Feijão-guandu com Rochagem (T6) o mesmo foi inferior ao tratamento T5 nas variáveis HP1', PM e RG (tabela 3).

O tratamento T6 somente foi superior ao tratamento T1 nas variáveis DC'1, PM e RG (tabela 3). Além disso, somente houve diferença entre os tratamentos T6 e T4 nas variáveis DC ${ }^{1}$ aos 30 DAS ao qual T6 foi superior (tabela 3), apresentando 0,049 cm contra 0,045 cm em T4, sendo que para a variável RG T6 obteve o resultado de $3174,6 \mathrm{~kg} \cdot \mathrm{ha}^{-1}$ e T4 $2362,8 \mathrm{~kg} \cdot \mathrm{ha}^{-1}$, nos demais tratamentos não houve diferença significativa. O tratamento T1 por não apresentar rochagem e adubação verde foi inferior a todos os demais nas variáveis PM e RG, apresentando 262,2 g e 1816,8 kg.ha-1 respectivamente, e igual ao tratamento T4 em PM o que demonstra a importância do manjo do solo para o incremento de produtividade na cultura do milho. Em outras variáveis como $\mathrm{MSM}, \mathrm{HP}^{2}, \mathrm{DC}^{2}$ ao final do experimento, $\mathrm{CE}$ e $\mathrm{DE}$ o tratamento $\mathrm{T} 1$ não diferiu dos tratamentos T2, T4, T5 e T6 (tabela 3).

\section{DISCUSSÃO}

A Mucuna-preta produziu uma grande quantidade de massa seca conforme apresentado na Tabela 3, sendo os tratamentos $\mathrm{T} 2$ e T5, 11,38 t.ha-1 e 14,52 t.ha-1, respectivamente, superiores aos encontrados por Almeida et al. (2011) que avaliaram o rendimento de biomassa de adubos verdes em cultivo solteiro e consorciado, obtendo valores de 9,0 t.ha- ${ }^{1}$ para o cultivo solteiro de Mucuna-preta. Mesma forma que Brito et al. (2017) avaliando a produção de biomassa de adubos verdes encontrou valores de 4,7 t.ha $^{-1}$ de massa seca de Mucuna-preta e Cavalcante et al. (2012) encontrou valores de 4,2 t.ha-1 para a planta adubadeira em questão. 
Brito et al. (2017), avaliando diferentes espécies de adubos verdes no estado do Mato Grosso do Sul não encontrou diferenças significativas entre os tratamentos, dentre eles a Mucuna-preta e o Feijão-guandu encontrando valores de 9,7 t.ha ${ }^{-1}$ e 4,7 t.ha-1 respectivamente, diferentemente dos resultados desde estudo, pois, o tratamento com guandu produziu maiores quantidades de biomassa comparado a Mucuna, 24,75 t.ha ${ }^{-1}$ e 11,38 t.ha-1 ${ }^{-1}$, respectivamente, sendo os resultados superiores aos encontrados pelos autores.

Neste experimento o Feijão-Guandu e a Mucuna-Preta tiveram boa adaptação as condições edafoclimáticas da região. A irrigação foi utilizada na fase de desenvolvimento, não havendo déficit hídrico durante o período, esses fatores podem ter contribuído positivamente para o crescimento das plantas e resultaram na produção grande quantidade de biomassa.

A Mucuna-preta se beneficiou com a aplicação da rochagem, pois no tratamento T5 houve maior produção de matéria seca comparado ao T2, sendo que a adubação verde com Mucuna-preta associada a rochagem com Gnaisse promove maior incremento de P no solo (CARVALHO, 2012), nutriente importante para culturas como o milho.

Para o feijão-guandu, o mesmo não foi observado como no tratamento com Mucuna-preta com rochagem, ou seja, com a rochagem a produção de massa seca do tratamento com feijão-guandu com rochagem (T6) foi inferior ao tratamento somente com Feijão-guandu (T3). Observa-se que a Mucuna-preta recobre totalmente o solo e fornece grandes quantidades de folhas secas durante o período vegetativo que podem favorecer a vida no solo, a formação de ácidos orgânicos e que pode ter contribuído com a mineralização do pó de rocha, e o fato da associação de rochagem com Mucuna-preta promover incremento de P no solo (CARVALHO, 2012).

A adubação verde contribuiu significativamente para a produção de massa seca do milho, sendo que a utilização da adubação verde proporcionou maior produção de biomassa, essa prática contribui muito para a qualidade do solo principalmente por conta do incremento de matéria orgânica antes do semeio, favorecendo assim a rotação de culturas através do fornecimento de biomassa sobre o solo, contribuindo com as qualidade físicas, químicas e biológicas do solo, através da melhoria em sua estrutura, fornecimento de nutrientes e incremento na biomassa microbiana dos solos (AMBROSANO et al., 2012; AGOSTINHO et al., 2017; MOURA et al., 2014; SILVA et al., 2011). Assis et al. (2021) avaliando a influência do feijão-guandu no município de Pacajá - PA em atributos químicos, físicos e biológicos do solo observou que esta cultura aumentos os níveis de Carbono Orgânico no solo, Matéria Orgânica, aumento nos valores de nitrogênio, além do aumento das colônias bacterianas (UFC), esses resultados reforçam os benefícios de sua utilização em sistemas de rotação de culturas.

Segundo Boddey et al. (2010) as Fabaceae tem um papel importante na fixação biológica de nitrogênio e a decomposição dos resíduos vegetais proporciona liberação lenta de nutrientes; o semeio do milho ocorreu 52 dias após o corte das plantas adubadeiras tempo suficiente para a decomposição da biomassa da adubação verde antes do semeio, o que resultou na liberação dos nutrientes logo após o semeio, favorecendo o crescimento inicial das plantas, expressando diferença em algumas variáveis analisadas aos 30 DAS. Albuquerque et al. (2013) observando o desenvolvimento inicial e final das plantas de milho verificou 
que ao final do experimento o tamanho não diferiu entre os tratamentos, sendo encontrado valores de 1,72 m para Feijão-guandu e 1,80 m para Mucuna-preta, os valores encontrados pelos autores foram inferiores aos encontrados neste experimento. No mesmo trabalho de Albuquerque et al. (2013), os autores aplicaram a dose de $80 \mathrm{~kg}$.ha ${ }^{-1}$ de nitrogênio e observaram diferenças significativas na altura das plantas de milho, destacando que somente a utilização da adubação verde não proporcionou diferenças para esta variável.

Rosa et al. (2011), avaliando a o desempenho do milho cultivado sob restos vegetais de leguminosas encontrou resultado semelhante quando avaliado o parâmetro de altura das plantas, não evidenciando diferenças significativas entre os tratamentos, obtendo valores de $287,5 \mathrm{~cm}$ para Feijão-guandu e $291,8 \mathrm{~cm}$ para Mucuna-preta contra $193 \mathrm{~cm}$ e $180 \mathrm{~cm}$ encontrados neste trabalho para Feijão - guandu e Mucunapreta, respectivamente, pôde-se observar que os resultados dos referidos autores foram superiores aos encontrados nesta pesquisa.

Estudos realizados por Padovan et al. (2015) no Mato Grosso do Sul, onde utilizou-se sete tipos de plantas de cobertura, dentre elas Feijão-guandu e Mucuna-preta, obteve maiores resultados, sendo os valores encontrados de 2,43 m e 2,48 m, respectivamente, para a variável altura. Este estudo corrobora com a pesquisa realizada em Brasil Novo - PA, no qual ambos não apresentarem diferenças significativas entre as leguminosas.

Para as plantas de cobertura e adubação verde não foi observado diferença significativa para o parâmetro avaliado de atura. Em estudos realizados por Albuquerque et al. (2013), Rosa et al. (2011) e Padovan et al. (2015), demonstrando a presença de igualdade sobre os tratamentos com leguminosas para esta variável, da mesma forma que neste estudo.

As análises das espigas proporcionam compreensão do tamanho e quantidade de grãos, neste experimento o CE apresentou-se semelhante entre todos os tratamentos, obtendo a maior média no tratamento T3 e a menor no tratamento T1. Pôde-se observar que a adubação verde com Feijão-guandu promove maior crescimento das espigas. Os resultados encontrados por Brito et al. (2017) não obteve diferenças para esta variável, encontrando valores de $10,5 \mathrm{~cm}$ e 9,6 cm para esta variável, sendo para Mucuna-preta e Feijão-guandu, respectivamente. Esses dados são inferiores aos obtidos nesta pesquisa. Albuquerque et al. (2013) obteve diferença estatística para a variável CE, 13,60 cm para Feijão-guandu e 13,45 cm para Mucuna, esses resultados são superiores aos encontrados neste trabalho.

O parâmetro de peso de mil grãos (PM) representa o tamanho dos grãos, assim como sua maturidade e sanidade (BRASIL, 2009), sendo o tratamento T1 o que apresentou menor PM. justificado pela ausência da adubação verde e rochagem e o tratamento T3 apresentou os maiores valores de PM (tabela 3).

A adubação verde com feijão-guandu promoveu maior incremento para essa variável e parâmetros de produtividade do milho, havendo diferença significativa neste experimento. Estudos realizados por Rosa et al. (2011) encontrou valores de $410 \mathrm{~g}$ para ambos os tratamentos, Feijão-guandu e Mucuna, esses valores são maiores aos encontrados neste experimento, demonstrando que adubação verde promove o maior aumento na qualidade e tamanho dos grãos. Albuquerque et al. (2013), comparando Feijão-guandu e Mucuna não encontraram diferenças significativas para a variável PM, obtendo 267,3 g e 263,6 g para Feijão- 
guandu e Mucuna, respectivamente, esses resultados são inferiores aos encontrados nesta pesquisa.

O parâmetro rendimento de grãos (RG) mostrou-se que quando submetidos adubação verde e/ou rochagem apresentaram produtividade superior à média do estado do Pará que é de $2879 \mathrm{~kg} \cdot \mathrm{ha}^{-1}$ (COSTA et al., 2017), assim ressaltando que as práticas de manejo a ser empregado no solo são de fundamental importância para manutenção de sua produtividade.

O tratamento T3 produziu $249 \%$ a mais que o tratamento T1 e $220 \%$ a mais que a média do estado, evidenciando que as práticas de manejo do solo, utilização de plantas de cobertura e as características edafoclimáticas do município, proporcionaram de forma positiva a produtividade da cultura do milho. Os valores encontrados nesta pesquisa são superiores aos obtidos por Rosa et al. (2011) que apresentou produtividade de 4956 kg.ha-1e 4831 kg.ha-1 para Mucuna e Feijão-guandu, respectivamente, não apresentando diferença estatística entre as espécies. Brito et al. (2017) encontrou valores de 1740,3 kg.ha${ }^{1}$ e 2156,6 kg.h $\mathrm{h}^{-1}$ para Mucuna e Feijão-guandu respectivamente, valores inferiores aos encontrados neste trabalho que foi de 6331,86 kg.h $\mathrm{h}^{-1}$ para Feijão-guandu e 3716,4 $6 \mathrm{~kg} \cdot \mathrm{h}^{-1}$ para Mucuna-preta, evidenciando o efeito do Feijão-guandu no incremento da produtividade, sendo superior e diferindo estatisticamente dos demais tratamentos estudados.

O tratamento somente com a rochagem obteve uma produtividade inferior à média do estado, com a dosagem de 2 t.ha-1 de pó de rocha, o que não proporcionou melhorias na nutrição das plantas de milho nas condições edafoclimáticas estudadas nesta pesquisa. O fator que mostra a redução da produção no tratamento com rochagem e sem adubação verde é o requerimento da cultura do milho pelo elemento mineral Nitrogênio, sendo este fundamental para o desenvolvimento da cultura e produção de grãos, a falta desse nutriente se torna fator limitante na produção (COSTA et al., 2012), e a presença de plantas leguminosas possibilita a reposição natural deste mineral ao solo e resulta em sua disponibilidade, principalmente pela capacidade de realizarem a fixação biológica do nitrogênio no solo (FRANÇA et al., 2011; BRITO et al., 2017).

Embora haja a presença de grandes quantidades de nutrientes no pó de rocha utilizado, o tratamento somente com a rochagem não apresentou resultados que diferissem do tratamento T1 sem rochagem e sem adubação verde. A eficiência agronômica do pó de rocha depende de condições do solo, tempo de incubação, origem do material, de tratamentos e das culturas utilizadas, sendo as vezes a possibilidade de utilização para nutrição inviável, principalmente pela baixa solubilidade do material (MARTINS et al., 2008). Hanisch et al. (2013), realizando coleta de solo após 9 meses da aplicação de rochagem não evidenciou efeitos sobre os atributos químicos solo, além disso, a aplicação da rocha também não influenciou na produtividade do milho após 3 anos de avaliação. Resultados semelhantes foram encontrados por Alovisi et al. (2017).

A utilização do pó de rocha proporcionou aumento em alguns parâmetros analisados na cultura do milho comparado ao tratamento T1, entretanto, a utilização de 2 t.ha ${ }^{-1}$, como recomentado por Martins et al. (2011), não proporcionou efeito de ganho nos parâmetros estudados que promovesse a recomendação nesta pesquisa como principal fonte de nutrição, havendo a necessidade de realizar consórcios com adubação verde ou realizar estudos com doses mais elevadas e /ou menores granulometrias. Esses 
questionamentos também foram levantados por Araújo et al. (2021), em trabalhos com dosagens de pó de diabásio penatecaua em mudas de cacaueiro.

A interação positiva entre adubação verde e rochagem foi observada por Pessatto et al. (2012) avaliando o efeito do pó de rocha e Crotalária, foi observado aumento nas variáveis altura, comprimento da espiga e altura de inserção da espiga. A decomposição da biomassa dos adubos verdes melhora algumas características no solo, como fornecimento de matéria orgânica e descompactação (SILVA et al., 2014), o que favorece o desenvolvimento das culturas.

A relação $\mathrm{C} / \mathrm{N}$ das leguminosas é baixa, o que favorece sua decomposição e consequentemente a formação de ácidos orgânicos nas camadas superficiais do solo (ROSA et al., 2017). Levando em consideração que a relação C/N da Mucuna-preta é de 17:1 (ESPINDOLA et al., 2005) e a do Feijão-guandu de 24:1 (CALVO et al., 2010) pode-se inferir que a decomposição da biomassa de Mucuna-preta contribuiu para a decomposição e mineralização do pó de rocha e favoreceu o desenvolvimento do milho, essa melhoria pode ter sido por meio dos nutrientes contidos no pó de rocha, pois o tratamento somente com Mucuna-preta (T2) não obteve os mesmos resultados.

O tratamento T6 (Feijão-guandu com rochagem) não apresentou o mesmo resultado do tratamento T5 (Mucuna- preta com rochagem), quando avaliadas as variáveis HP1, PM, RG observa-se que os maiores resultados foram obtidos no solo manejado com Mucuna-preta + rochagem, principalmente no parâmetro produtividade. Tal fato pode ser justificado pela decomposição mais rápida da Mucuna-preta quando comparado ao Feijão-guandu, que pode ter favorecido a mineralização do pó de rocha, uma vez que o Feijãoguandu por ser mais lento devido a maior relação $\mathrm{C} / \mathrm{N}$. No tratamento $\mathrm{T} 6$ o pó de rocha não promoveu o desenvolvimento do Feijão-guandu, que por sua vez não influenciou no quesito rendimento de grãos que expressa a produtividade do milho através da forma de manejo, pois os melhores resultados apresentados foram os que tiveram o manejo do solo somente com feijão-guandu sem rochagem, promovendo o melhor desenvolvimento agronômico do milho.

\section{CONCLUSÕES}

O feijão-guandu promoveu maior produção de biomassa e consequentemente maior concentração e incremento de matéria orgânica ao solo, sendo observado o melhor crescimento e desenvolvimento do milho neste tratamento. Entretanto a aplicação da rochagem isoladamente não promoveu o melhor desempenho para a cultura do milho, mas associada com a adubação verde, especificamente com a Mucunapreta mostrou-se como uma alternativa para potencializar sua ação.

\section{REFERÊNCIAS}

AGOSTINHO, P. R.; GOMES, S. S.; GALLO, A. S.; GUIMARÃES, N. F.; GOMES, M. S.; SILVA, R. F.. Biomassa microbiana em solo adubado com vinhaça e cultivado com milho safrinha em sucessão a leguminosas. Acta Iguazu, Cascavel, v.6, n.3, p.31-43, 2017. DOI:

http://doi.org/10.48075/actaiguaz.v6i3.16259
ALBUQUERQUE, A. W.; SANTOS, J. R.; MOURA, G. M.; REIS, L. S.. Plantas de cobertura e adubação nitrogenada na produção de milho em sistema de plantio direto. R. Bras. Eng. Agríc. Ambiental, Campina Grande, v.17, n.7, p.721726, 2013. DOI: http://doi.org/10.1590/S141543662013000700005 
ALOVISI, A. M. T.; FRANCO, D.; ALOVISI, A. A.; TOKURA, L. K.; SILVA, S. R.. Atributos de fertilidade do solo e produtividade de milho e soja influenciados pela rochagem. Edição Especial: II Seminário de Engenharia de Energia na Agricultura. Acta Iguazu, Cascavel, v.6, n.5, p.57-68, 2017. DOI: http://doi.org/10.48075/actaiguaz.v6i5.18470

ALMEIDA, K.; CAMARA, F. L. A.. Produtividade de biomassa e acúmulo de nutrientes em adubos verdes de verão, em cultivos solteiros e consorciados. Revista Brasileira de Agroecologia, v.6, n.2, 2011.

AMBROSANO, E. J.; GUIRADO, N.; ROSSI, F.; SCHAMMASS, E. A.; AMBORSANO, G. M. B.; DIAS, F. L. F.. Alterações químicas no solo na sucessão de milho verde/adubo verde e milho verde/tomate. Apta Regional, Campinas, v.9, n.2, p.1-5, 2012.

ARAÚJO, M. L. M.; SILVA, S. A. S.; FARIAS, V. D. S.; TREVISAN, M. H.; LOBATO, A. A. C.; CORDEIRO, C. B.; SILVA, R. O.; LIMA, G. G.. Use of crushing reside as nutrients source in the cocoa see dling development in Medicilândia-PA. International Journal for Onnovation Education and Research, v.9, n.6, p.426-441, 2021. DOI:

http://doi.org/10.31686/ijier.vol9.iss6.3186

ASSIS, J. M.; SILVA, S. A. S.; LISBOA, S. C. L.; FARIAS, V. D. S.; NOGUEIRA, A. S.; SANTOS, M. A. S.. Atributos físicos, químicos e biológicos do solo sob influência do feijão guandu cajanus cajan (L. Millsp.) no município de Pacajá, Pará, Brasil. In: REDIN, E.. Ciências Rurais em Foco Belo Horizonte - MG: Volume 2. Poisson, 2021. p.42-51. DOI: http://doi.org/10.36229/978-65-5866-066-8.CAP.06

BATISTA, M. A. V.; NETO, F. B.; AMBRÓSIO, M. M. Q.; GUIMARÃES, L. M. S.; SARAIVA, J. P. B.; SILVA, M. L.. Atributos microbiológicos do solo e produtividade de rabanete influenciados pelo uso de espécies espontâneas. Horticultura Brasileira, Brasília, v.31, n.4, p.587-594, 2013. DOI: http://doi.org/10.1590/S0102-05362013000400013

BRASIL. Ministério da Agricultura, Pecuária e Abastecimento. Regras para análises de sementes. Brasília: MAPA, 2009.

BRASIL. Plano diretor de desenvolvimento sustentável de Brasil Novo - 2011, Brasil Novo, PA. P.M.B.N., 2011.

BRASIL, E. C.; CRAVO, M. S.; VIÉGAS, I. J. M.. Recomendações de calagem e adubação para o estado do Pará. 2 ed. Brasília: EMBRAPA, 2020.

BRITO, M. F.; TSUJIGUSHI, B. P.; ROCHA, D. P.; SILVA, R. F.. Reciclagem de nutrientes de adubos verdes e produtividade de milho cultivado em sucessão em agroecossistema de transição agroecológica. Acta Iguazu, Cascavel, v.6, n.3, p.11-21, 2017. DOI:

http://doi.org/10.48075/actaiguaz.v6i3.17669.

BODDEY, R. M.; JANTALIA, C. P.; CONCEICÃO, P. C.; ZANATTA, J. A.; BAYER, C.; MIELN ICZUK, J.; DIECKOW, J.; SANTOS, H. P.; DENARDIN, J. E.; AITA, C.; GIACOMINI, S. J.; ALVES, B. J. R.; SEGUNDO, U.. Carbonaccumulationatdepth in Ferralsolsunder zero-till subtropical agriculture. Global Change Biology, v.16, p.784-795, 2010. DOI: http://doi.org/10.1111/i.1365-2486.2009.02020.x.

CARVALHO, A. M. X.. Rochagem e suas interações no ambiente solo: contribuições para aplicação em agroecossistemas sob manejo agroecológico. Tese (Doutorado em Solos e Nutrição de Plantas) - Universidade Federal de Viçosa, Viçosa, 2012.

CALVO, C. L.; FOLONI, J. S. S.; BRANCALIÃO, S. R. Produtividade de Fitomassa e Relação $\mathrm{C} / \mathrm{N}$ de Monocultivos e Consórcios de Guandu-Anão, Milheto e Sorgo em Três Épocas de Corte. Bragantia, Campinas, v.69, n.1, p.77-86, 2010

CAVALCANTE, V. S.; SANTOS, V. R.; NETO, A. L. S. SANTOS, M. A. L.; SANTOS, C. G.; COSTA, L. C.. Biomassa e extração de nutrientes por plantas de cobertura. Revista Brasileira de Engenharia Agrícola e Ambiental, Campina Grande, v.16, n.5, p.521-528, 2012. DOI: http://doi.org/10.1590/S141543662012000500008

CONAMA. Conselho Nacional do Meio Ambiente. Resolução № 420, de 28 de dezembro de 2009. Dispõe sobre critérios e valores orientadores de qualidade do solo quanto à presença de substâncias químicas e estabelece diretrizes para o gerenciamento ambiental de áreas contaminadas por essas substâncias em decorrência de atividades antrópicas. Brasília: MMA, 2009.

COSTA, N. R.; ANDREOTTI, M.; GAMEIRO, R. A.; PARIZ, C. M.; BUZETTI, S.; LOPES, K S. M.. Adubação nitrogenada no consórcio de milho com duas espécies de braquiária em sistema plantio direto. Pesquisa Agropecuária Brasileira, Brasília, v.47, n.9, p.1038- 1047, 2012. DOI: http://doi.org/10.1590/S0100-204X2012000800003.

COSTA, M. R. T. R.; HOMMA, A. K. O.; REBELLO, F. K.; FILHO, A. P. S. S.; FERNANDES, G. L. C.; BALEIXE, W.. Atividade Agropecuária no Estado do Pará. Empresa Brasileira de Pesquisa Agropecuária. Documentos 432. Belém: Embrapa Amazônia Oriental, 2017.

FAO. Organização das Nações Unidas Para Agricultura. Projeto da FAO e Ministério do Meio Ambiente buscará combater a desertificação em áreas degradadas. FAO, 2018.

EMBRAPA. Empresa Brasileira de Pesquisa Agropecuária. BRS 4157: Sol-da-manhã NF. Seropédica: Centro Nacional de Pesquisa de Agrobiologia; Sete Lagoas: Centro Nacional de Pesquisa de Milho e Sorgo; Brasília: Serviço de Produção de Sementes Básicas, 1990.

ESPINDOLA, J. A. A.; GUERRA, J. G. M.; POLLI, H.; ALMEIDA, D. L.; ABBOUND, A. C. S.. Adubação verde com leguminosas. Brasília: Embrapa Informação Tecnológica, II - (Coleção Saber), 2005.

FRANÇA, S.; MIELNICZUK, J.; ROSA, L. M. G.; BERGAMASHI, H.; BERGONICI, J. L.. Nitrogênio disponível ao milho: Crescimento, absorção e rendimento de grãos. Revista Brasileira de Engenharia Agrícola e Ambiental, Campina Grande, v.15, n.11, p.1143-1151, 2011. DOI: http://doi.org/10.1590/S1415-43662011001100006.

HANISCH, A. L.; FONSECA, J. A.; JUNIOR, A. A. B.; SPAGNOLLO, E.. Efeito de pó de basalto no solo e em culturas anuais durante quatro safras, em sistema de plantio direto. Revista Brasileira de Agropecuária Sustentável (RBAS), v.3, n.2. p.100-107, 2013. Dol: http://doi.org/10.21206/rbas.v3i2.224 
HENRIQUES, F. S.. A revolução verde e a biologia molecular. Rev. de Ciências Agrárias, Lisboa, v.32, n.2, p.245-254, 2009.

LEITE, C. D.; MEIRA, A. L.; MOREIRA, V. R. R.. Calda de Cinza e Cal. Fichas Agroecológicas. Tecnologias Apropriadas para Agricultura Orgânica. Sanidade Vegetal 18. Brasília: MAPA, 2016.

LONGO, R. M.; RIBEIRO, A. Í.; MELO, W. J.. Uso da adubação verde na recuperação de solos degradados por mineração na floresta amazônica. Bragantia, Campinas, v.70, n.1, p.139146, 2011. DOI: http://doi.org/10.1590/S0006$\underline{87052011000100020}$

IBGE. Instituto Brasileiro de Geografia e Estatística. Mapa do clima do Brasil. Rio de Janeiro: IBGE, 2002.

MARTINS, G.; GUTTERRES, L. M.; VIANA, P. R.. Práticas agroecológicas na agricultura familiar. Ação Nascente Maquiné. Maquiné-RS, 2011.

MARTINS, E. S.; OLIVEIRA, C. G.; RESENDE, A. V.; MATOS, M. S. F.. Agrominerais - Rochas Silicáticas como Fontes Minerais Alternativas de Potássio para a Agricultura. In: LUZ, A. B.; LINS, F. A. F.. Rochas e minerais industriais. 2 ed. Rio de Janeiro: CETEM, 2008. p.205-223.

MATZEMBACHER, D. E.; MEIRA, F. B.. Mercantilização \& contramovimento: agricultura sustentada pela comunidade (CSA): estudo de caso em Minas Gerais, Brasil. Organizações \& Sociedade, v.27, n.94, 2020. DOI: http://doi.org/10.1590/1984-9270942

MIRANDA, A. A. C.. Relação entre indicadores de qualidade do solo sob diferentes sistemas de manejo. Dissertação (Mestrado em Agroecologia) - Universidade Federal da Paraíba, Bananeiras, 2018.

MOURA, E. G.; AGUIAR, A. C. F.. Adubação verde e manejo sustentável do solo na Amazônia. In: FILHO, O. F. L.; AMBROSANO, E. J.; ROSSI, F.; CARLOS, J. A. D.. Adubação verde e plantas de cobertura no Brasil: fundamentos e práticas. Volume 2. Brasília: Embrapa, 2014.

OLIVEIRA, I. J.; FONTES, J. R. A.; BARRETO, J. F.; PINHEIRO, J. $O$. C.. Recomendações técnicas para o cultivo de milho no
Amazonas. Circular Técnica 68. Manaus: EMBRAPA, 2018.

PADOVAN, M. P.; CARNEIRO, L. F.; FELISBERTO, G.; NASCIMENTO, J. S.; CARNEIRO, D. N. M.. Milho cultivado em sucessão a adubos verdes em sistemas sob bases agroecológicas. Revista Agro@mbiente, v.9, n.4, p.377-385, 2015. DOI: http://dx.doi.org/10.18227/19828470ragro.v9i4.2705

PESSATTO, T. C.; VIEIRA, A. O.; SOARES, A. P.; STEINKE, M. C. K.; GRIESANG, J. L.; LACERDA, A. R.. Desempenho agronômico do milho cultivado em sucessão à crotalária e cama de frango em diferentes espaçamentos. In: CONGRESSO NORTE E NORDESTE DE PESQUISA E INOVAÇÃO. Anais. Palmas, 2012.

PINHEIRO, S.. Saúde do Solo: Biopoder camponês versus agronegócio. Rio Grande do Sul: Salles, 2015.

ROSA, D. M.; NÓBREGA, L. H. P.; LIMA, G. P.; MAULI, M. M.. Desempenho da cultura do milho implantada sobre resíduos culturais de leguminosas de verão em sistema plantio direto. Seminário: Ciências Agrárias, Londrina, v.32, n.4, p.12871295, 2011.

ROSA, D. M.; NÓBREGA, L. H. P.; MAULI, M. M.; LIMA, G. P.; PACHECO, F. P.. Substâncias húmicas do solo cultivado com plantas de cobertura em rotação com milho e soja. Revista Ciência Agronômica, Fortaleza, v.48, n.2, p.221-230. 2017. DOI: http://doi.org/10.5935/1806-6690.20170026

SILVA, E. C.; MURAOKA, T.; BUZETTI, S.; ARF, O.; SÁ, M. E.; AMBROSANO, E. J.. Ciclagem de nutrientes e fornecimento de nitrogênio por adubos verdes para o arroz de sequeiro cultivado em sucessão, em um Latossolo Vermelho de Cerrado. Cadernos de Agroecologia, Fortaleza, v.6, n.2, 2011.

SILVA, S. A. S.; SILVA, A. C. M. E.; GONÇALVES, D. B.; LEÃO, F. M.. Avaliação da matéria orgânica e pH do solo em sistemas agroflorestais localizados na região de Altamira-PA. Agrarian Academy: Centro Científico Conhecer, Goiânia, v.1, n.2, p.15-25, 2014.

TEIXEIRA, P. C.; DONAGEMMA, G. K.; FONTANA, A.; TEIXEIRA, W. G.. Manual de Métodos de Análise de Solo. 3 ed. Brasília: EMBRAPA, 2017.

A CBPC - Companhia Brasileira de Produção Científica (CNPJ: 11.221.422/0001-03) detém os direitos materiais desta publicação. Os direitos referem-se à publicação do trabalho em qualquer parte do mundo, incluindo os direitos às renovações, expansões e disseminações da contribuição, bem como outros direitos subsidiários. Todos os trabalhos publicados eletronicamente poderão posteriormente ser publicados em coletâneas impressas sob coordenação da Sustenere Publishing, da Companhia Brasileira de Produção Científica e seus parceiros autorizados. Os (as) autores (as) preservam os direitos autorais, mas não têm permissão para a publicação da contribuição em outro meio, impresso ou digital, em português ou em tradução. 